\title{
Desafios para o planejamento e a gestão metropolitanos na Amazônia: uma abordagem introdutória
}

\author{
Helena Lúcia Zagury Tourinho ${ }^{1}$ e Marlon Lima da Silva ${ }^{2}$
}

1 Arquiteta e Urbanista, Dra. em Desenvolvimento Urbano pela Universidade Federal de Pernambuco, Professora e pesquisadora do Programa de Pós-Graduação em Desenvolvimento e Meio Ambiente Urbano da Universidade da Amazônia, Brasil. E-mail: helenazt@uol.com.br

2 Geógrafo, M.Sc. em Geografia pela Universidade Federal do Pará, Professor Substituto da Universidade Federal do Pará, Brasil. E-mail: marlon.angelim@yahoo.com.br

RESUM O: Até a Constituição Brasileira de 1988, cabia à União a atribuição de criar regiões metropolitanas no país. Com a transferência de tal responsabilidade para os Estados pela Carta Magna, uma série de novas regiões metropolitanas foi instituída, seguindo critérios diversos e respondendo a interesses bastante variados. A Amazônia, que possuía apenas a Região Metropolitana de Belém, criada em 1973 com dois municípios, hoje conta com nove regiões metropolitanas bastante diversificadas em termos demográficos, socioeconômicos e geográficos, abrangendo 69 municípios. Em janeiro de 2015, com o advento do Estatuto da Metrópole (Lei Federal 13.089/2015), um conjunto de obrigações foi imposto aos Estados e municípios metropolitanos, dentre os quais os de: definição das funções públicas de interesse comum; estabelecimento de sistema de governança interfederativa com participação da sociedade civil; e elaboração e implantação do Plano de Desenvolvimento Urbano Integrado. 0 presente artigo visa a introduzir o debate sobre o planejamento, a gestão e a execução das funções públicas de interesse comum metropolitano nas regiões metropolitanas formalmente instituídas na região com base no Estatuto da M etrópole. Após apresentar o conceito de região metropolitana, traça um breve histórico sobre a institucionalização das regiões metropolitanas no Brasil e na Amazônia e mostra as mudanças recentes no arcabouço jurídico nacional. Por fim, apresenta as principais determinações do Estatuto da M etrópole e suas implicações para os estados e municípios metropolitanos amazônicos.

Palavras-chave: Região Metropolitana. Planejamento Metropolitano. Gestão Metropolitana. Amazônia. Brasil.

Planning and management metropolitan challenges in the Amazon: an initial approach ABSTRACT: Until 1988 Brazilian Constitution, it was Federal the responsibility for metropolitan region creation. The 'Carta Magna' transferred such obligation to States. Therefore, various new metropolitan regions were created, considering several and distinct criteria and interests. Amazonia holds only Belém M etropolitan Region, created in 1973 with only two counties. Nowadays, it has 9 metropolitan regions, very diverse in demographic, social, economic, and geographic aspects, upholding 69 counties. The 'Estatuto da Metrópole' was approved in January 2015 (Federal Law 13.089/2015) implying to states and counties a hall of obligations, e.g.: common interest functions definition; establishment of a system for inter federation governance with social participation; and Integrated Urban Development Plan elaboration and implementation. This paper aims to establish a debate on planning, management, and execution of common interest functions in the Amazon formal metropolitan regions, on 'Estatuto da Metróple' basis. After presenting metropolitan region concept, it brings up history on formation of such re- 
gions in Brazil and Amazônia, in order to show recent changes in concerning laws and their implication to amazon states and metropolitan counties. Finally, paper shows main challenges faced by amazon metropolitan regions in attending "Estatuto da M etrópole" demands.

Keywords: Metropolitan Region. Metropolitan Planning. Metropolitan Management. Amazon. Brazil.

\section{INTRODUÇÃO}

A Constituição Federal de 1988, em seu Art. 25, remeteu aos Estados a responsabilidade de criar Regiões Metropolitanas - RMs, "constituídas por agrupamentos de municípios limítrofes, para integrar a organização, o planejamento e a execução de funções públicas de interesse comum" (BRASIL, 1988).

$\mathrm{Na}$ ausência de um critério nacional unificado para definir região metropolitana e estabelecer os parâmetros mínimos para a sua constituição e composição, uma grande quantidade de regiões metropolitanas foram instituídas pelas unidades da federação no país, e outras tantas foram ampliadas, fazendo com que, às nove regiões metropolitanas criadas em 1973-74, fossem acrescidas mais sessenta e duas regiões, e a quantidade de municípios metropolitanos totalizasse 1.208 unidades em 2014.

Em janeiro de 2015 foi sancionada a Lei Federal № 10.089, chamada de Estatuto da Metrópole que:

[...] estabelece diretrizes gerais para o planejamento, a gestão e a execução das funções públicas de interesse comum em regiões metropolitanas e aglomerações urbanas instituídas pelos Estados, normas gerais sobre o plano de desenvolvimento urbano integrado e outros instrumentos de governança interfederativa, e critérios para o apoio da União a ações que envolvam governança interfederativa no campo do desenvolvimento urbano. (BRASIL, 2015)

O que acorreu com as Regiões Metropolitanas na Amazônia após a Constituição Federal de 1988? Quais são as regiões metropolitanas instituídas na Amazônia atualmente e como estas se encontram integradas? Que avanços e desafios o Estatuto da M etrópole coloca para estas regiões metropolitanas? 0 presente artigo visa a introduzir o debate sobre o planejamento, a gestão e a execução de funções públicas de interesse comum pelas regiões metropolitanas formalmente instituídas na Amazônia face à aprovação do Estatuto da Metrópole. Após apresentar o conceito de região metropolitana, traça um breve histórico sobre a institucionalização das regiões metropolitanas no Brasil e na Amazônia para mostrar as mudanças recentes no arcabouço jurídico nacional e suas implicações para os estados e municípios metropolitanos amazônicos. Por fim aponta os principais desafios a serem enfrentados pelas RM s da Amazônia diante das determinações do Estatuto da Metrópole. 


\section{METRÓPOLE, REGIÃO E REGIÃO METROPOLITANA.}

0 acelerado processo de urbanização do país tem revelado uma série de problemas que se manifestam com intensidade, sobretudo, nas grandes cidades. Dificuldades de mobilidade urbana, destinação inadequada dos resíduos sólidos, carências habitacionais, dentre outros, assumiram dimensão e complexidade tão expressiva que extrapolaram as próprias fronteiras municipais, estendendo-se para além dos limites político-administrativos destas unidades da federação.

A necessidade de enfrentamento de problemas urbanos na escala supramunicipal, tem motivado, desde a década e 1970, a instituição de leis para definir, orientar e fomentar o planejamento e a gestão de espaços denominados de metropolitanos. Mas, afinal, o que é metrópole e o que é região metropolitana? M etrópole e região metropolitana são a mesma coisa? Todas as metrópoles integram, necessariamente, regiões metropolitanas? E para existir uma região metropolitana, é preciso haver metrópole?

Qualquer tentativa de definição única de metrópole e de região metropolitana está fadada ao insucesso, já que "o que é metropolitano para uma ciência pode não sêlo para outra" (ALVES, 1998, p. 03). Ademais, o que é considerado metropolitano num dado momento não significa que o é em todos os demais. Metrópole e região metropolitana, portanto, devem ser consideradas mediante múltiplos aspectos, dependendo das abordagens teóricas usadas, do momento histórico, assim como dos objetivos funcionais subjacentes à necessidade de definição.

Esses apontamentos indicam pelo menos dois caminhos a serem percorridos na definição de metrópole e de região metropolitana: o filosófico-científico e o pragmático-operacional. Enquanto o primeiro se volta para os conceitos, fundamentos, particularidades e generalidades do fenômeno, o segundo segue o percurso dos parâmetros, critérios e leis usados para defini-lo e delimitá-lo.

No campo conceitual a metrópole hoje é entendida como a cidade principal de uma região, o nó de comando e de coordenação da rede urbana, que se destaca não só pelo tamanho e/ ou concentração populacionais e econômicos, como também pelo desempenho de funções complexas e diversificadas (multifuncionalidade), assim como pelas relações que mantém com outras metrópoles ou aglomerações urbanas (LENCIONI, 2006; KAYSER, 1980).

A presença de uma metrópole, ou seja, de uma cidade-polo comandando uma região, é um pressuposto para a existência de uma região metropolitana; é o que a distingue das aglomerações urbanas, onde os centros urbanos pertencentes a mais de um município, conurbados ou não, são concorrentes ou mais equilibrados entre si. Mas, a presença de um nó de comando regional não implica, necessariamente, a ocorrência de fenômeno metropolitano que justifique a criação de uma região metropolitana. 
Do ponto de vista conceitual, a instituição de uma região metropolitana pressupõe haver relações intermunicipais intensas e cotidianas, que gerem a necessidade de ações compartilhadas no campo do planejamento, da gestão e da execução de determinadas funções. Não de funções socioeconômicas gerais, mas daquelas de natureza urbana.

A esse respeito cabe citar Coutinho, Pinto e Cruz (2009, p. 4), ao afirmarem que 0 que determinou a criação das regiões metropolitanas:

[...] não foi nenhum fato regional, mas uma realidade urbana, com abrangência territorial sobre vários M unicípios. [...]. Aliás, neste particular, outros países preferiram, em vez de região, denominá-las de "áreas metropolitanas" referindo-se à área territorial abrangida pela cidade, ou metrópole. Apesar das denominações o desafiante é a cidade, não a sua área ou região de abrangência.

Da junção dos conceitos de região e de metrópole emerge, então, a ideia de região metropolitana como sendo a área composta por mais de um município que apresenta tamanho urbano expressivo e intensa rede de fluxos urbanos intermunicipais, gerada em decorrência da concentração de empregos e de atividades de comércio e serviços, sobretudo na cidade-polo, ou seja, na metrópole.

As regiões metropolitanas,

[...] são formadas, na verdade, por realidades socioeconômicas, culturais e políticas, de natureza urbana e que abrangem e integram, simultaneamente, vários Municípios. 0 desafio não está neste aspecto territorial, mas na gestão integrada desse ente, que é comum às várias municipalidades. (COUTINHO, PINTO e CRUZ, p.4-5)

Com base neste conceito, a abordagem pragmática-operacional vê a região metropolitana como um espaço definido por Lei, formado por municípios com fronteiras político-administrativas contíguas, que se unem para o desenvolvimento de ações de interesse comum. Nesta perspectiva, os parâmetros e critérios considerados para a delimitação da região metropolitana, para o planejamento, a gestão e a execução das ações a serem compartilhadas assumem relevância peculiar.

A necessidade de tratamento compartilhado das chamadas funções públicas de interesse comum metropolitano, doravante conhecidas como FPICs, é o que particulariza e que dá sentido operacional ao conceito de região metropolitana.

Organizar, planejar e executar funções públicas de interesse comum, notadamente onde o pacto federativo não contempla uma instância intermediária entre estado e município, como é o caso brasileiro, envolve um conjunto de aspectos de extrema complexidade. Não implica apenas em criar e institucionalizar essas áreas ou regiões definindo os municípios que a constituem. É fundamental, também, a criação de uma estrutura de governança interfederativa, que contemple: as competências dos entes 
que integram a estrutura metropolitana; as fontes de recursos para os investimentos nesta escala; e, a definição de como vai ser compartilhado e distribuído o poder decisório entre os diversos entes envolvidos.

Para entender como o Estatuto da M etrópole enfrentou estas questões e as repercussões das suas determinações nas RMs da Amazônia é preciso, primeiramente, entender como as regiões metropolitanas vêm sendo tratadas no Brasil e na região Amazônica.

\section{INSTITUCIONALIZAÇÃO DE REGIÕES METROPOLITANAS NO BRASIL}

Prevista desde a Constituição Federal de 1967, no Brasil, as regiões metropolitanas só foram criadas, formalmente, nos anos 1970, em um contexto político centralizador e autoritário em que imperou o planejamento tecnocrático.

Assim, as primeiras regiões metropolitanas foram instituídas pela União, mediante as Leis Complementares Federais no 14/1973 e no 20/1974, sendo elas: São Paulo, Belo Horizonte, Porto Alegre, Recife, Salvador, Curitiba, Belém, Fortaleza e Rio de Janeiro. A Região M etropolitana de Belém - RM B, a única localizada na Amazônia, era a menor região do país em termos de quantidade de municípios e de tamanho popu|acional ${ }^{1}$, sendo composta, então, pelos municípios de Belém e Ananindeua, que juntos, segundo dados do Censo de 1970, somavam 669.768 mil habitantes.

o modelo de sistema gestor metropolitano instituído expressou o contexto político da época. De acordo com as leis federais, as RM s deveriam possuir um Conselho Consultivo, presidido pelo Governador do Estado, e um Conselho Deliberativo. 0 primeiro com as funções de promover a elaboração do Plano de Desenvolvimento Integrado e a programação dos serviços comuns da região, assim como de coordenar a execução dos programas e projetos comuns. 0 segundo, com as competências de opinar, "quando demandado pelo Conselho Deliberativo", sobre questões metropolitanas, e de "sugerir", também ao Conselho Deliberativo, a formulação de planos e providências relacionadas à execução dos serviços comuns (BRASIL, 1973).

Como serviços comuns de interesse metropolitano foram estabelecidos, dentre outros: o planejamento integrado do desenvolvimento econômico e social; o saneamento básico; o uso do solo metropolitano; transportes e sistema viário; a produção e $o$ transporte de gás canalizado; e 0 aproveitamento dos recursos hídricos e o controle da poluição ambiental.

A partir destas determinações legais, vários estados implantaram seus sistemas de gestão metropolitana, inclusive o Pará, os quais atingiram seus apogeus nos anos 1970 e início dos anos 1980, quando ainda havia recursos federais alimentando os fundos metropolitanos destinados para financiar a realização de planos e de obras

\footnotetext{
${ }^{1} \mathrm{Na}$ época com mais de seis milhões e meio de habitantes estavam as regiões metropolitanas de São Paulo e Rio de Janeiro; ente 1 e 2 milhões de habitantes totalizavam as de Recife, Belo Horizonte, Porto Alegre, Salvador e Fortaleza; e, com menos de 1 milhão apenas Curitiba e Belém.
} 
que envolviam mais de um município. A partir da crise dos anos 1980, e da consequente redução dos repasses de recursos federais para os fundos e entidades metropolitanas, a maioria dos sistemas gestores metropolitanos passou por processos de esvaziamento, alguns até de progressiva desativação, como o caso paraense.

O marco para a mudança no tratamento da questão metropolitana no Brasil foi a Constituição Federal de 1988 que, no seu Art. 25, definiu:

$\S 30$ - Os Estados poderão, mediante lei complementar, instituir regiões metropolitanas, aglomerações urbanas e microrregiões, constituídas por agrupamentos de municípios limítrofes, para integrar a organização, o planejamento e a execução de funções públicas de interesse comum. (BRASIL, 1988)

Como a Constituição Federal e nenhum outro instrumento legal da União, não estabeleceu uma definição legal de região metropolitana a ser adotada no país, e nem instituiu parâmetros mínimos para sua criação e composição, o legislativo de cada Estado passou a adotar conceitos e critérios diferenciados para instituir e/ ou ampliar as suas regiões metropolitanas, assim como para estabelecer seus respectivos sistemas de gestão.

No período de 1988 a 2014, uma grande quantidade de regiões metropolitanas surgiu no país, e outras tantas foram ampliadas, fazendo com que, às nove regiões metropolitanas criadas em 1973-74, fossem acrescidas mais sessenta e duas. Se em 1974 havia 118 municípios metropolitanos, no Brasil, em 2014, conforme dados do Ministério das Cidades, 1.208 municípios brasileiros já o eram, abrigando uma população de 96.770 .521 habitantes que correspondia a mais do que quatro vezes o total das regiões metropolitanas em 1970, que era de 23.643.734 (BRASIL. Ministério das Cidades, 2015).

Contribuiu para o crescimento desordenado de regiões metropolitanas brasileiras a difusão, entre as representações políticas estaduais e locais, da ideia de que, integrando uma região metropolitana, os municípios teriam maior facilidade de obter recursos dos governos federal e estadual para viabilizar obras e ações. Esta ideologia ganhou força no país, especialmente após a abertura de algumas linhas de financiamento voltadas para municípios metropolitanos do Programa de Aceleração do Crescimento (PAC) e do Programa M inha Casa M inha Vida (PM CM V). Como consequência, muitos municípios brasileiros assumiram o status de metropolitano sem estar inseridos em fenômenos metropolitanos.

Em termos de distribuição espacial, as regiões metropolitanas que se localizavam principalmente na faixa litorânea e na região Sul e Sudeste, se internalizaram no território nacional e se disseminam em várias unidades da federação (Figura 1). 0 estado de Santa Catarina, por exemplo, se converteu em um estado totalmente metropolitano. 


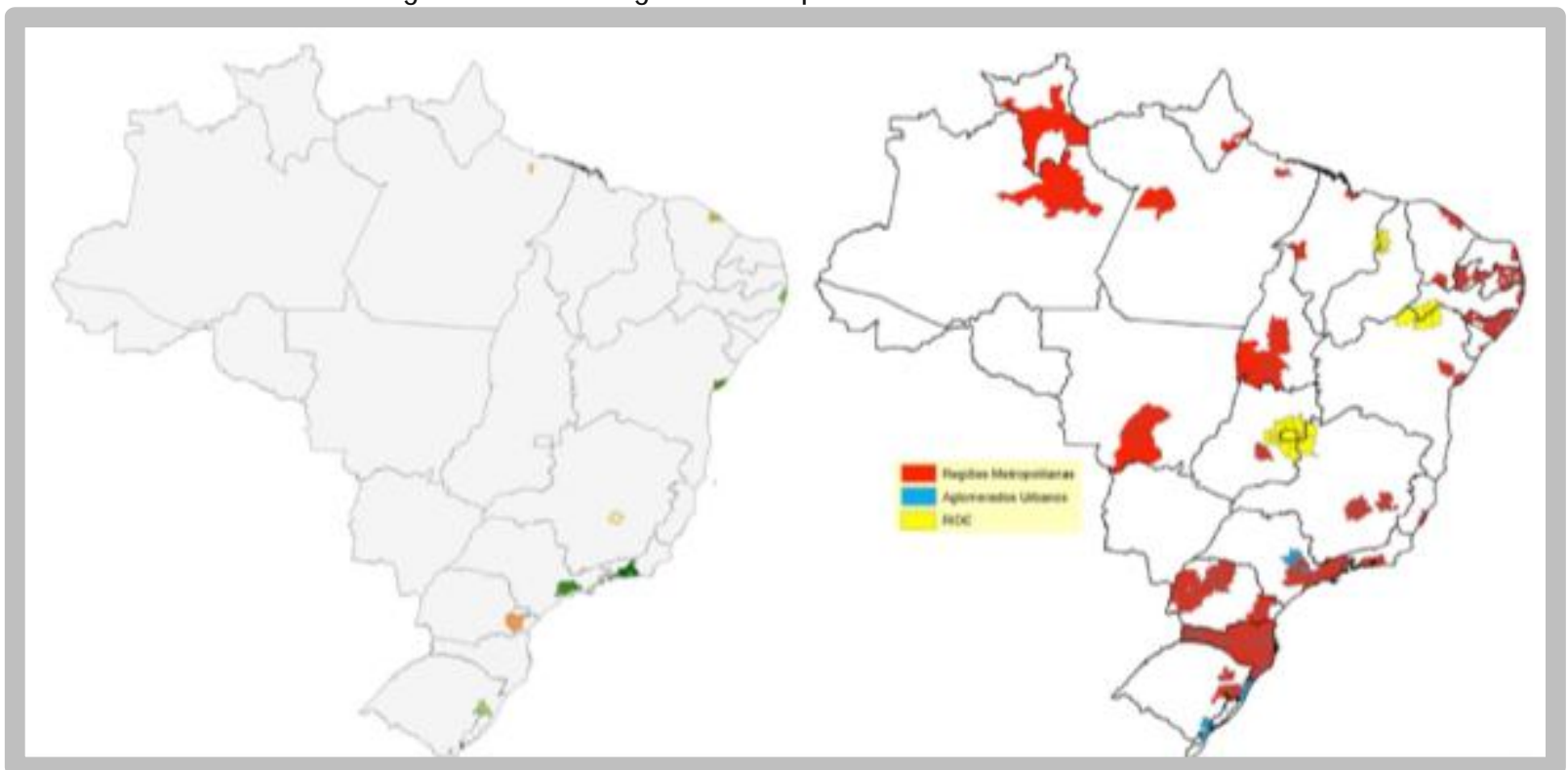

Fonte: Brasil. M inistério das Cidades (2015).

0 movimento de criação e ampliação de regiões metropolitanas teve manifestações relevantes na Amazônia. De uma única região metropolitana - a de Belém, criada em 1973 e composta pelos municípios paraenses de Belém e Ananindeua -, a Região Norte passou a ter nove regiões metropolitanas, integradas agora por sessenta e nove municípios e distribuídas em cinco estados da federação (Tabela 1 e Figura 2).

\begin{tabular}{|c|c|c|}
\hline Estado & Regiläo Metropolitana & Ne de municipios \\
\hline Amapá & Macapá & 2 \\
\hline Amazonas & Manaus & 13 \\
\hline \multirow{3}{*}{ Roraima } & Boa Vista & 2 \\
\hline & Central & 2 \\
\hline & Sul de Roraima & 3 \\
\hline \multirow{2}{*}{ Pará } & Belém & 10 \\
\hline & Santarém & 3 \\
\hline \multirow{2}{*}{ Tocantins } & Gurupi & 16 \\
\hline & Palmas & 18 \\
\hline
\end{tabular}

Fonte: IBGE 
Figura 2: Região Norte - Regiões M etropolitanas

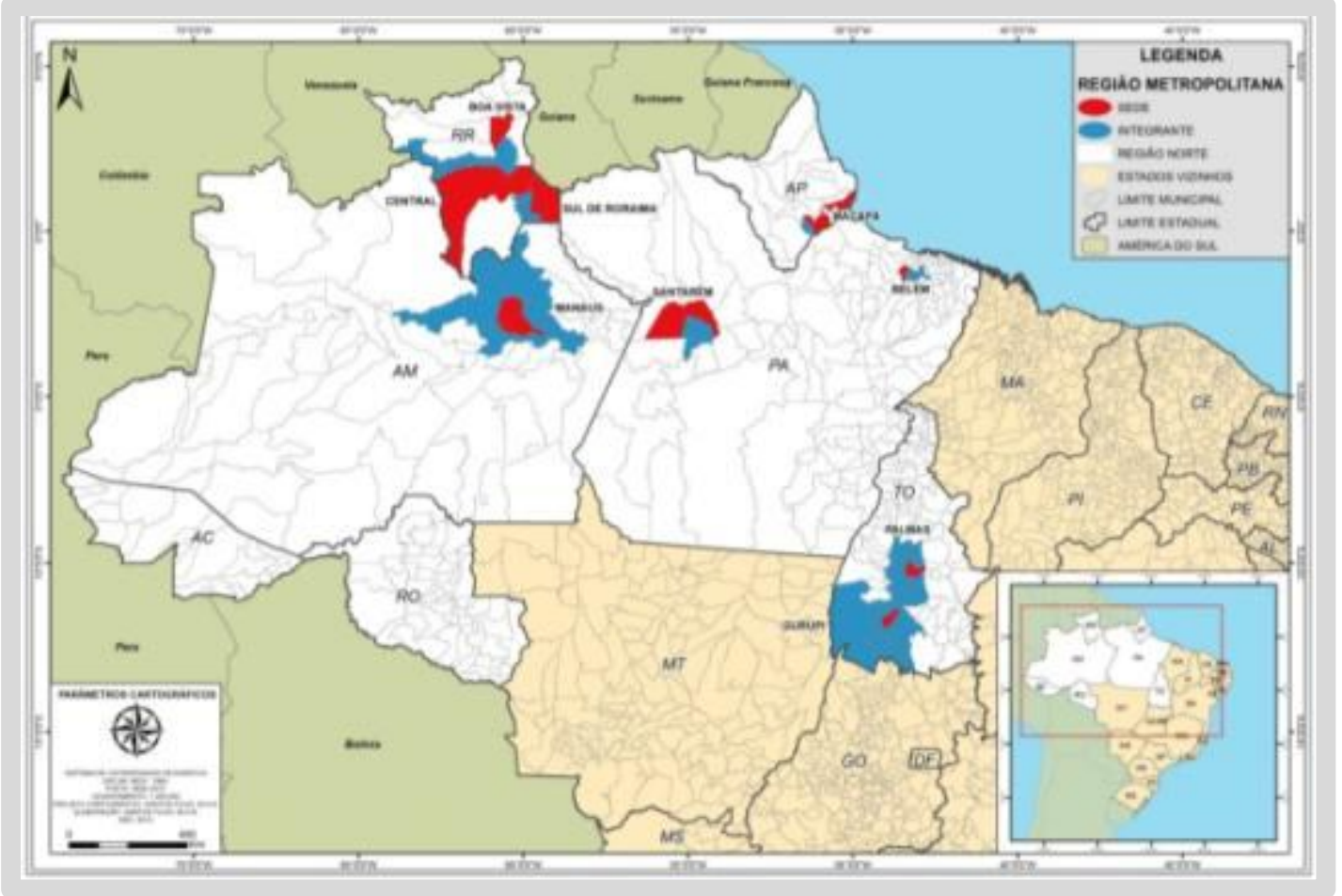

Fonte: SEDOP/DDMET

Elaboração: M ario Hélio Nunes dos Santos Filho.

Ressalte-se que, em muitos casos, as definições e os critérios usados para a criação e/ou a ampliação de regiões metropolitanas no país, em especial na Amazônia, não foram claramente explicitados. Da mesma forma, não são raros os casos em que os sistemas de gestão e governança não foram instituídos ou, quando o foram, não chegaram a ser implantados.

O Quadro 1 apresenta, de maneira sintética, o conteúdo das leis que criaram as regiões metropolitanas da Amazônia. 
Quadro 1 - Região Norte; Leis de criação e ampliação das regiões metropolitanas.

\begin{tabular}{|c|c|c|c|c|c|}
\hline UF & $\begin{array}{l}\text { RMS } \\
\text { LEIS }\end{array}$ & FPICS & SISTEM A GESTOR & $\begin{array}{l}\text { FUNDO METRO- } \\
\text { POLITANO }\end{array}$ & $\begin{array}{l}\text { PLANO ME } \\
\text { TROPOLITANO }\end{array}$ \\
\hline & $\begin{array}{l}\text { MACAPÁ } \\
\text { Lei Com- } \\
\text { plementar } \\
\text { Estadual } \\
n^{\circ} 21 / 2003\end{array}$ & Não prevê & Não prevê. & Não prevê. & Não prevê \\
\hline & $\begin{array}{l}\text { MANAUS } \\
\text { Lei Com- } \\
\text { plementar } \\
\text { Estadual } \\
n^{\circ} 52 / 2007\end{array}$ & $\begin{array}{l}\text { O art. 3o define as funções } \\
\text { públicas e os serviços que } \\
\text { atendam a mais de um Mu- } \\
\text { nicípio, e os que, mesmo } \\
\text { restritos ao território de um } \\
\text { deles, sejam de algum modo } \\
\text { dependente, concorrentes, } \\
\text { confluentes, especialmente: } \\
\text { a) planejamento integrado } \\
\text { do desenvolvimento eco- } \\
\text { nômico e social; } \\
\text { b) saneamento básico; } \\
\text { c) transporte coletivo in- } \\
\text { termodal; } \\
\text { d) distribuição de gás canali- } \\
\text { zado; } \\
\text { e) aproveitamento, prote- } \\
\text { ção e utilização racional e } \\
\text { integrada dos recursos hí- } \\
\text { dricos; } \\
\text { f) conservação ambiental, } \\
\text { manejo e desenvolvimento } \\
\text { sustentável dos recursos } \\
\text { naturais; } \\
\text { g) informações cartográficas } \\
\text { para o planejamento me- } \\
\text { tropolitano; } \\
\text { h) habitação. }\end{array}$ & $\begin{array}{l}\text { O art. 40 prevê um Conselho } \\
\text { de Desenvolvimento Susten- } \\
\text { tável da RM M (CDSRM M) } \\
\text { composto por: } \\
\text { a) Governador do Estado } \\
\text { (Presidente); } \\
\text { b) } 12 \text { membros do Executi- } \\
\text { vo Estadual; } \\
\text { c) Prefeitos dos municípios } \\
\text { integrantes; } \\
\text { d) Presidente da Assembleia } \\
\text { Legislativa Estadual; } \\
\text { e) } 1 \text { membro da Câmara } \\
\text { Municipal de Manaus; } \\
\text { f) } 1 \text { membro representan- } \\
\text { do as demais Câmaras Mu- } \\
\text { nicipais; } \\
\text { g) } 1 \text { membro da sociedade } \\
\text { civil organizada. } \\
0 \text { art. } 50 \text { define que o Con- } \\
\text { selho deverá elaborar } 0 \\
\text { Plano de Desenvolvimento } \\
\text { Integrado da RM M, além de } \\
\text { estabelecer normas gerais } \\
\text { sobre a execução dos servi- } \\
\text { ços comuns de interesse } \\
\text { metropolitano e o seu cum- } \\
\text { primento e controle. }\end{array}$ & $\begin{array}{l}0 \text { art. } 11 \text { o define } \\
\text { os recursos que } \\
\text { irão custear es- } \\
\text { tudos, projetos, } \\
\text { obras e ativida- } \\
\text { des, que são: } \\
\text { a) recursos da } \\
\text { União, Estado e } \\
\text { Municípios. } \\
\text { b) recursos pro- } \\
\text { venientes de } \\
\text { receitas auferi- } \\
\text { das no mercado } \\
\text { financeiro. } \\
\text { c) transferên- } \\
\text { cias, a fundo } \\
\text { perdido, prove- } \\
\text { nientes de enti- } \\
\text { dades públicas } \\
\text { ou privadas, } \\
\text { nacionais, es- } \\
\text { trangeiras ou } \\
\text { internacionais. } \\
\text { d) recursos pro- } \\
\text { venientes de } \\
\text { fundo estadual } \\
\text { especialmente } \\
\text { criado para tal } \\
\text { fim. pa }\end{array}$ & $\begin{array}{l}\text { Prevê que } 0 \\
\text { Conselho } \\
\text { Gestor que } \\
\text { deverá } \\
\text { elaborar o } \\
\text { Plano de } \\
\text { Desenvol- } \\
\text { vimento } \\
\text { Integrado } \\
\text { da Região } \\
\text { Metropoli- } \\
\text { tana de } \\
\text { Manaus. }\end{array}$ \\
\hline
\end{tabular}




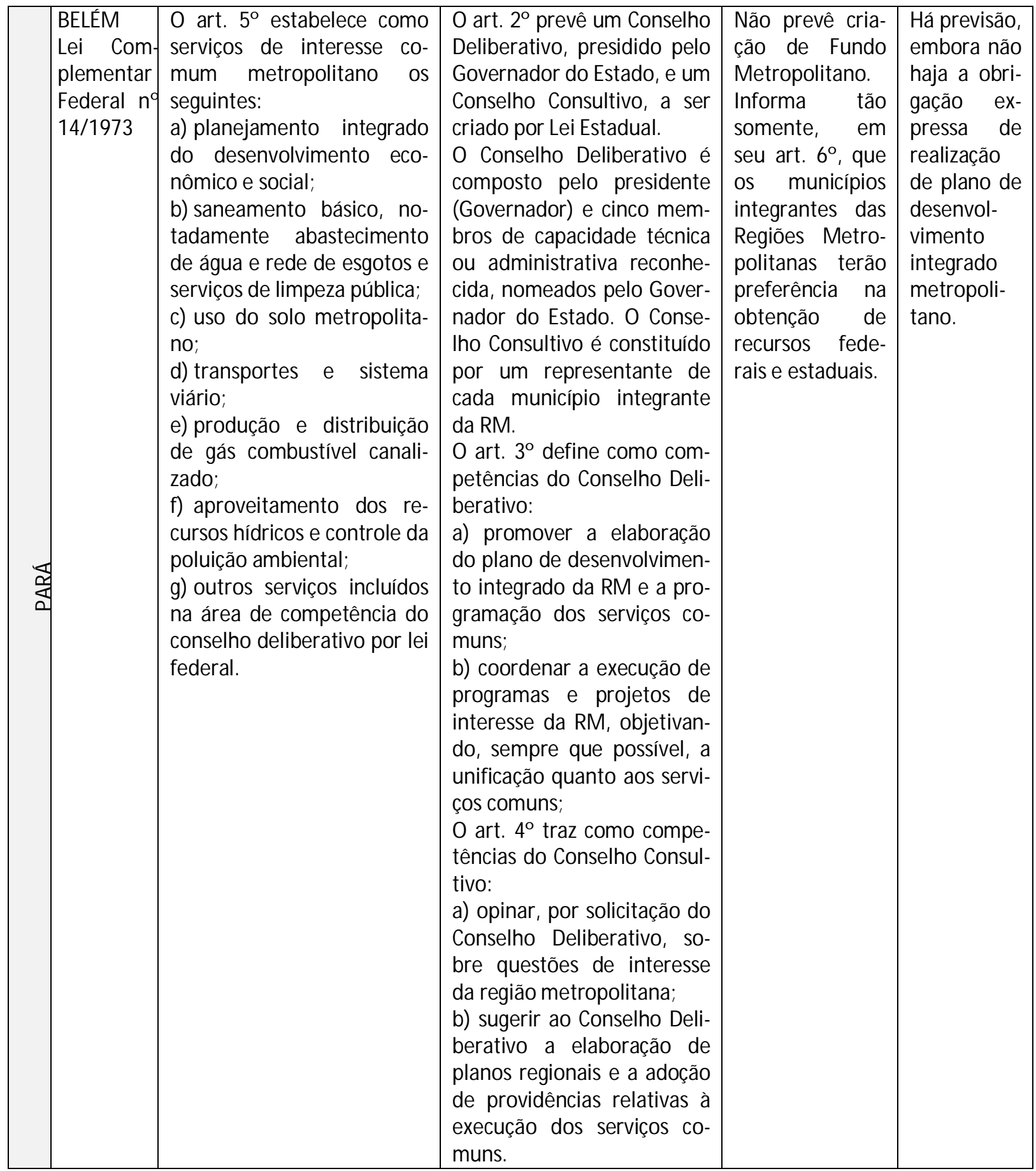




\begin{tabular}{|c|c|c|c|c|c|}
\hline & \begin{tabular}{|l|} 
BELÉM \\
Lei Com- \\
plementar \\
Estadual \\
$n^{\circ} 027 / 199$ \\
5
\end{tabular} & $\begin{array}{l}\text { O art. 5o determina que } \\
\text { haverá unificação da execu- } \\
\text { ção de serviços comuns, a } \\
\text { qual será efetuada por meio } \\
\text { de concessão dos serviços } \\
\text { da entidade estadual ou } \\
\text { pela constituição de empre- } \\
\text { sa de âmbito metropolitano, } \\
\text { através de convênio ou } \\
\text { outros processos que ve- } \\
\text { nham a ser estabelecidos. } \\
\text { A Lei não discrimina quais } \\
\text { são as Funções Públicas de } \\
\text { Interesse Comum. }\end{array}$ & $\begin{array}{l}\text { O art. } 2 \text { o define o Conselho } \\
\text { Metropolitano com a se- } \\
\text { guinte constituição: } \\
\text { a) Governador do Estado } \\
\text { (Presidente); } \\
\text { b) Secretário de Estado de } \\
\text { Planejamento (Vice - Presi- } \\
\text { dente); } \\
\text { c) Presidente da ALEPA; } \\
\text { d) Prefeitos dos Municípios } \\
\text { integrantes; } \\
\text { d) Presidentes das Câmaras } \\
\text { de Vereadores dos Municí- } \\
\text { pios Integrantes. } \\
0 \text { art. 3o define que as nor- } \\
\text { mas regulamentadoras e as } \\
\text { competências deste Conse- } \\
\text { lho deverão constar em } \\
\text { Decreto. } \\
0 \text { art. 6o informa que o } \\
\text { Conselho Metropolitano } \\
\text { disporá de seu regimento } \\
\text { interno. }\end{array}$ & $\begin{array}{l}0 \text { art. } 40 \text { cria o } \\
\text { Fundo de De- } \\
\text { senvolvimento } \\
\text { da RM de Be- } \\
\text { lém, cuja receita } \\
\text { será determina- } \\
\text { da pelo conse- } \\
\text { lho metropoli- } \\
\text { tano. } \\
0 \text { art. 5o estabe- } \\
\text { lece que os } \\
\text { municípios inte- } \\
\text { grantes das } \\
\text { Regiões Metro- } \\
\text { politanas terão } \\
\text { preferências na } \\
\text { obtenção de } \\
\text { recursos fede- } \\
\text { raise estaduais. }\end{array}$ & Não prevê. \\
\hline & $\begin{array}{l}\text { SANTA- } \\
\text { RÉM } \\
\text { Lei Com- } \\
\text { plementar } \\
\text { Estadual } \\
\text { no } \\
079 / 2012\end{array}$ & Não prevê. & Não prevê. & Não prevê. & Não prevê. \\
\hline 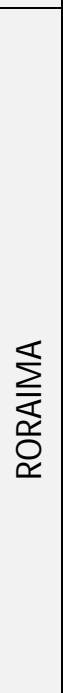 & \begin{tabular}{|l|} 
BOA \\
VISTA \\
CENTRAL \\
SUL DE \\
RORAIM A \\
Lei Com- \\
plementar \\
Estadual \\
$n^{\circ} 130 / 200$ \\
7
\end{tabular} & Não prevê. & Não prevê. & $\begin{array}{l}0 \text { art. 70 institui } \\
\text { que as despesas } \\
\text { decorrentes da } \\
\text { aplicação da } \\
\text { presente Lei } \\
\text { decorrerão do } \\
\text { orçamento do } \\
\text { Estado e Muni- } \\
\text { cípios, bem } \\
\text { como, dos con- } \\
\text { vênios que se- } \\
\text { jam firmados } \\
\text { com objetivos } \\
\text { comuns aos } \\
\text { envolvidos e } \\
\text { interessados. }\end{array}$ & Não prevê. \\
\hline
\end{tabular}




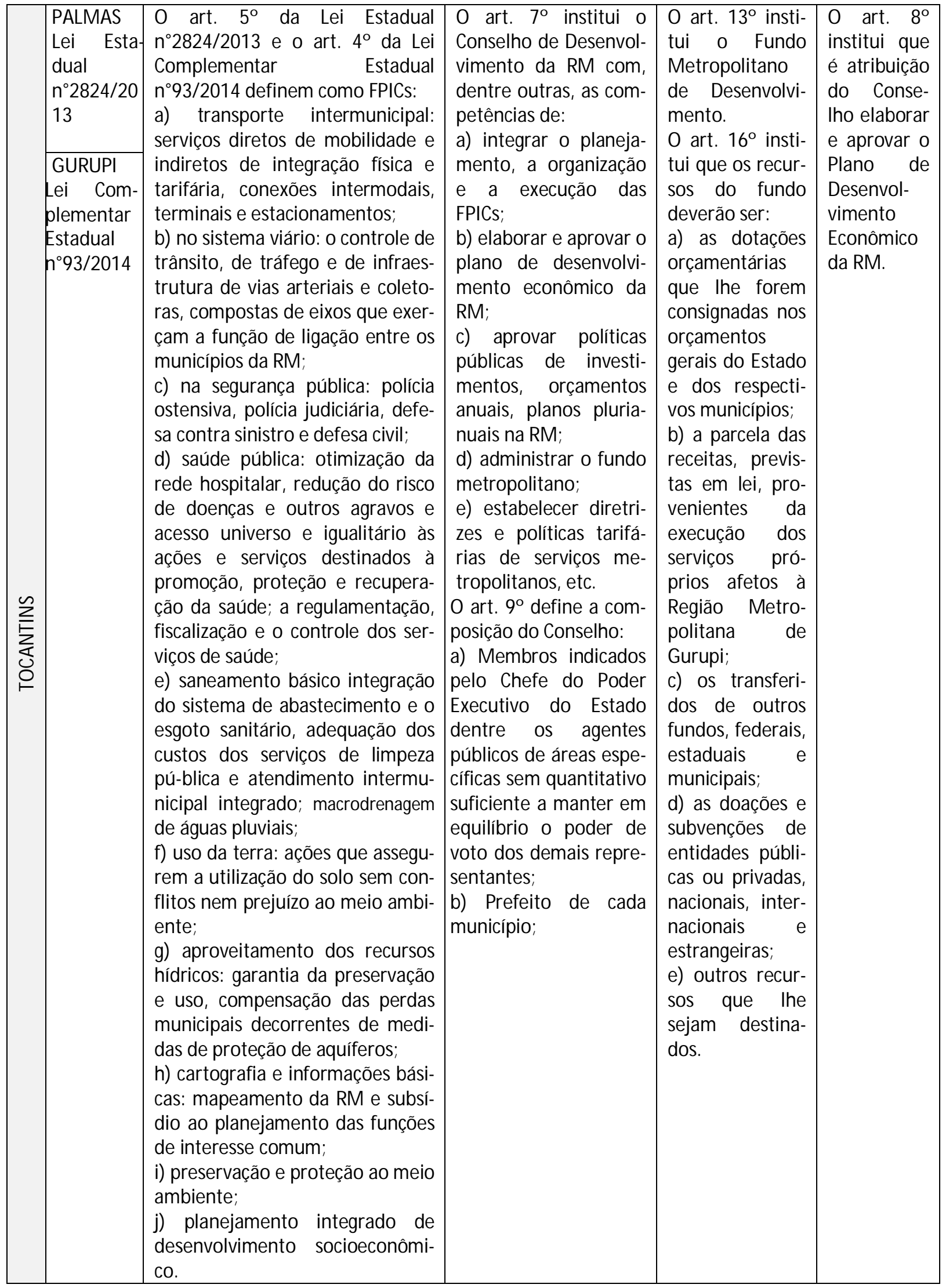

Fonte: Elaborado pelos autores. 
Uma breve e introdutória análise do mesmo permite constatar que, nem todas as leis que criaram e ampliaram as regiões metropolitanas amazônicas contêm requisitos necessários para a governança plena metropolitana, tais como a explicitação das FPICs, a definição de sistema de planejamento e gestão com a participação da sociedade civil; e a indicação de mecanismos de financiamento e controle dos investimentos em ações metropolitanas. Além disso, mesmo quando estes constam nas Leis das RMs instituídas, não significa que os mesmos já foram implantados e que estejam funcionando adequadamente.

À medida que os recursos governamentais federais destinados às regiões metropolitanas brasileiras foram escasseando e que os Ministérios se viram obrigados a incorporar outros critérios de seleção face à diversidade de realidades socioespaciais que passaram a se intitular como regiões metropolitanas, o impulso inicial de criação e ampliação de regiões metropolitanas foi diminuindo. Para este freio, teve papel fundamental, também, a sanção do Estatuto da M etrópole.

\section{ESTATUTO DA METRÓPOLE E REGIÕES METROPOLITANAS AMAZÔNICAS}

Após mais de 10 anos de tramitação ${ }^{2}$, o Senado aprovou, em 17/12/2014, o Estatuto da Metrópole, que estabelece diretrizes para o planejamento, a gestão e a execução das FPICs em regiões metropolitanas, além de normas gerais sobre o Plano de Desenvolvimento Urbano Integrado e outros instrumentos de governança interfederativa.

Menos de um mês depois, por meio da Lei Federal no 13.089, de 12 de janeiro de 2015, o referido Estatuto foi sancionado pela Presidência da República, rapidez que surpreendeu os acadêmicos, técnicos e gestores de instituições públicas que discutiram este tema no legislativo federal desde 2004, quando o primeiro projeto foi encaminhado ao Congresso Nacional ${ }^{3}$.

Um primeiro aspecto digno de ser notado no Estatuto foi a tentativa de estabelecimento de um conceito de região metropolitana, e de, por essa via, a tentativa tardia de corrigir as distorções que haviam se instalado no país após a lacuna deixada pela Constituição Federal de 1988. De acordo com o Estatuto da Metrópole (BRASIL, 2015):

\footnotetext{
${ }^{2} 0$ histórico de tramitação do Estatuto da Metrópole na Câmara de Deputados pode ser visualizado em http://www25.senado.leg.br/web/atividade/materias/-/materia/116471.

${ }^{3}$ Originalmente proposto no Projeto de Lei 3.460/2004 de autoria do deputado federal Walter Feldman,0 Estatuto da Metrópole recebeu 48 emendas e foi objeto de: quatro audiências públicas, realizadas na Câmara dos Deputados; quatro fóruns regionais de debates ocorridos em São Paulo, Goiânia, Salvador e Florianópolis; e, duas rodadas de reuniões técnicas. Desse processo participativo resultou um projeto substitutivo, apresentado em novembro de 2013 pelo deputado federal Zezéu Ribeiro, relator da comissão especial que tratou do assunto. (http://www.caubr.gov.br/?p=36402).
} 
a) região metropolitana é "aglomeração urbana que configure uma metrópole" (Art., $\mathrm{VII})$;

b) aglomeração urbana é a "unidade territorial urbana constituída pelo agrupamento de dois ou mais municípios limítrofes, caracterizada por complementaridade funcional e integração das dinâmicas geográficas, ambientais, políticas e socioeconômicas (Art. 2이 I); e

c) metrópole é "o espaço urbano com continuidade territorial que, em razão de sua população e relevância política e socioeconômica, tem influência nacional ou sobre uma região que configure, no mínimo, a área de influência de uma capital regional, conforme os critérios adotados pela Fundação Instituto Brasileiro de Geografia e Estatística - IBGE" (Art.2ํㅡ, V).

0 que define a região metropolitana, então, é a presença de uma metrópole no agrupamento de municípios, e o que determina se uma cidade é metrópole é a posição/função da sede do município na rede urbana nacional, que deve ser, no mínimo, de capital regional. Com isso, em última instância, transferiu-se para a Fundação IBGE a responsabilidade de apontar onde pode haver região metropolitana e quais os municípios que podem ser sede de região metropolitana, posto que, a este Instituto cabe estabelecer os critérios e a metodologia, assim como desenvolver os estudos de hierarquização da rede urbana nacional.

Se por um lado, num quadro de ausência de critérios nacionais uniformizados para definir região metropolitana, foi positivo o Estatuto ter estipulado o patamar hierárquico mínimo para a cidade ser sede de região metropolitana, por outro lado, a adoção de tal critério poderá gerar, em alguns centros regionais que hoje não são metropolitanos, a expectativa de virem a se tornar sedes de regiões metropolitanas, mesmo sem apresentar o fenômeno metropolitano. Dito de outra forma, ao definir a sede metropolitana por um critério de polarização de natureza microrregional, sem indicar critérios urbanos para a inserção dos demais municípios em regiões metropolitanas, o Estatuto acabou colaborando para manter ou ampliar a confusão entre os conceitos de microrregião e região metropolitana.

As responsabilidades pelo planejamento e a gestão metropolitanos, que até então eram basicamente atribuídas aos Governos Estaduais, a partir de agora passam a ser compartilhadas entre os entes federativos e devem contar com a participação da sociedade civil. Isso significa que, além de observar as diretrizes gerais estabelecidas no Art. $2^{0}$ do Estatuto das Cidades (Lei 10.257/2001), os municípios, conforme o Art. 7o do Estatuto da Metrópole deverão consolidar diretrizes de:

I - implantação de processo permanente e compartilhado de planejamento e de tomada de decisão quanto ao desenvolvimento urbano e às políticas setoriais afetas às funções públicas de interesse comum;

II - estabelecimento de meios compartilhados de organização administrativa das funções públicas de interesse comum; 
III - estabelecimento de sistema integrado de alocação de recursos e de prestação de contas;

IV - execução compartilhada das funções públicas de interesse comum, mediante rateio de custos previamente pactuado no âmbito da estrutura de governança interfederativa;

V - participação de representantes da sociedade civil nos processos de planejamento e de tomada de decisão, no acompanhamento da prestação de serviços e na realização de obras afetas às funções públicas de interesse comum;

VI - compatibilização dos planos plurianuais, leis de diretrizes orçamentárias e orçamentos anuais dos entes envolvidos na governança interfederativa;

VII - compensação por serviços ambientais ou outros serviços prestados pelo Município à unidade territorial urbana, na forma da lei e dos acordos firmados no âmbito da estrutura de governança interfederativa.

Ressalte-se que para ser considerada com gestão plena e ter acesso ao apoio do governo federal para ações de governança interfederativa, a região metropolitana deve estar formalizada e delimitada por lei complementar estadual, possuir estrutura de governança implantada e ter Plano de Desenvolvimento Urbano Integrado (PDUI).

Todas as regiões metropolitanas deverão possuir um PDUI, que deverá ser desenvolvido no âmbito da estrutura de governança metropolitana e aprovado por meio de lei estadual. Este plano deve contemplar, no mínimo: as diretrizes para as FPICs, incluindo projetos estratégicos e ações prioritárias para investimento; o macrozoneamento da unidade territorial urbana; as diretrizes quanto à articulação dos municípios no parcelamento, uso e ocupação no solo urbano; as diretrizes relacionadas à articulação intersetorial das políticas públicas afetas à região metropolitana; a delimitação das áreas com restrições à urbanização visando à proteção do patrimônio ambiental ou cultural; e o sistema de acompanhamento e controle das disposições do referido plano.

Está prevista como penalidade a improbidade administrativa aos governadores ou agentes públicos que atuem na estrutura de governança interfederativa, e que deixem de elaborar e aprovar, por lei complementar, o PDUI das regiões metropolitanas no prazo de três anos. No caso das regiões instituídas antes do Estatuto, tal prazo é contado a partir da entrada em vigor do Estatuto, ou seja, se encerra no dia 11 de janeiro de 2018, restando um período bastante exíguo, especialmente ao se considerar todas as indefinições ainda presentes e a necessidade de regulamentação requerida para a implantação dos instrumentos elencadosno Estatuto.

Da mesma maneira, está prevista a improbidade administrativa aos Prefeitos que não compatibilizarem o Plano Diretor ao PDUI, no prazo de 3 anos após a aprovação do PDUI mediante lei estadual. Vale destacar aqui a forma como a prática de elaboração de planos vem sendo imposta às Prefeituras do país, muitas das quais, como as da Amazônia, sem qualquer estrutura financeira e técnica de recursos humanos para 
adotá-la. Para se ter uma ideia da dimensão do problema, a ser cumprida a agenda federal, os municípios metropolitanos deveriam ter:

a) Plano Diretor Participativo elaborado até 2006 e revisto até 10 anos depois (Lei Federal 10.257 de 10 de julho de 2001, conhecida como Estatuto da Cidade);

b) Plano de Habitação de Interesse Social aprovado até final de 2010 (Lei Federal 11.124 de 16 de junho de 2005), para o município poder aderir ao Sistema Nacional de Habitação de Interesse Social, requisito para acessar o Fundo Nacional de Habitação de Interesse Social;

c) Plano de Resíduos Sólidos aprovado até o dia 02 de agosto de 2014 (Lei Federal 12.305 de 2 de agosto de 2010);

d) Plano de Saneamento Básico instituído até dia 31 de dezembro de 2015 (Lei Federal 11.445 de 05 de janeiro de 2007, Decreto Federal 7.217 de 21 de julho de 2010 e Decreto Federal 8.211 de 21 de março de 2014), recentemente prorrogado para 31 de dezembro de 2017 (Decreto Federal 8.629/2015); e,

e) Plano de Mobilidade Urbana, aprovado em abril de 2015 (Lei Federal 12.587, de 03 de janeiro de 2013).

Assim sendo, os municípios de regiões metropolitanas, que aprovaram seus planos diretores em 2006 e que não dispõem de plano metropolitano ou que seus planos não contenham os requisitos mínimos definidos no Estatuto deverão, até o final de 2016, rever seus planos diretores; até 11 de janeiro de 2018, compartilhar a elaboração do PDUI; até 2021, revisar novamente o plano diretor municipal para adaptá-lo ao PDUI.

Como a grande maioria dos municípios da Amazônia, que dispõem de recursos escassos e frágil tradição em planejamento, atendem a essa obrigação sem apoio financeiro e técnico dos Estados e da União?

Ressalte-se que o projeto de que deu origem ao Estatuto da Metrópole previa a criação de um Fundo Nacional de Desenvolvimento Urbano Integrado (FNDUI), com a finalidade de captar recursos financeiros para apoiar as ações de governança interfederativa. Os recursos do Fundo viriam de verbas públicas e de contribuições e doações de pessoas físicas ou jurídicas, entidades e organismos de cooperação nacionais e internacionais.

Ocorre que a seção que tratava do FNDUI no Estatuto foi totalmente vetada pela Presidência da República. Com isso, permanece no ar a pergunta: Quem financiará as ações da governança interfederativa, inclusive as de elaboração e implantação dos PDUIs? Até o presente, não existe nenhuma ação do Governo Federal voltada para capacitar os estados e municípios, nem para financiar os processos de implantação das estruturas de governança e a formulação dos PDUIs.

Ademais, uma vez garantido estes recursos, será possível cumprir o prazo legal previsto para fazê-los? Esta questão se torna particularmente relevante quando se leva em consideração os instrumentos que as regiões metropolitanas terão disponíveis para promover o planejamento a gestão e a execução das FPICs. 
Além do PDUI, foram previstos outros instrumentos para a gestão compartilhada, dentre eles: as operações urbanas consorciadas interfederativas; zonas para aplicação compartilhada dos instrumentos urbanísticos previstos no Estatuto das Cidades; os consórcios públicos, convênios de cooperação, contratos de gestão; as parcerias público-privadas interfederativas; e a compensação por serviços ambientais. Grande parte destes instrumentos ainda requer regulamentação e implica em elevada complexidade de implantação.

Só para dar uma ideia da dificuldade de aplicação desses instrumentos, até o presente momento, o município de Belém não conseguiu regulamentar instrumentos previstos no Plano Diretor M unicipal de 2008, como a outorga onerosa do direito de construir, a operação urbana consorciada e o IPTU progressivo no tempo. Além disso, não conseguiu implantar uma operação urbana consorciada. Como pensar instrumentos na escala interfederativa quando não se conseguiu avançar sequer na escala municipal?

A considerar os critérios estabelecidos no Estatuto da Metrópole, os municípios que, de acordo com o estudo mais recente de Região de Influência das Cidades (REGIC) do IBGE, teriam condições para ser sede de região metropolitana na Amazônia, são: Rio Branco, no Acre; Macapá, no Amapá; M anaus, no Amazonas; Belém, Marabá e Santarém, no Pará; Boa Vista, em Roraima; Porto Velho em Rondônia; Palmas, Imperatriz e Araguaína, no Tocantins (ver Figura 3).

Figura 3: M etrópoles e capitais regionais da Amazônia de acordo com o REGIC, 2007

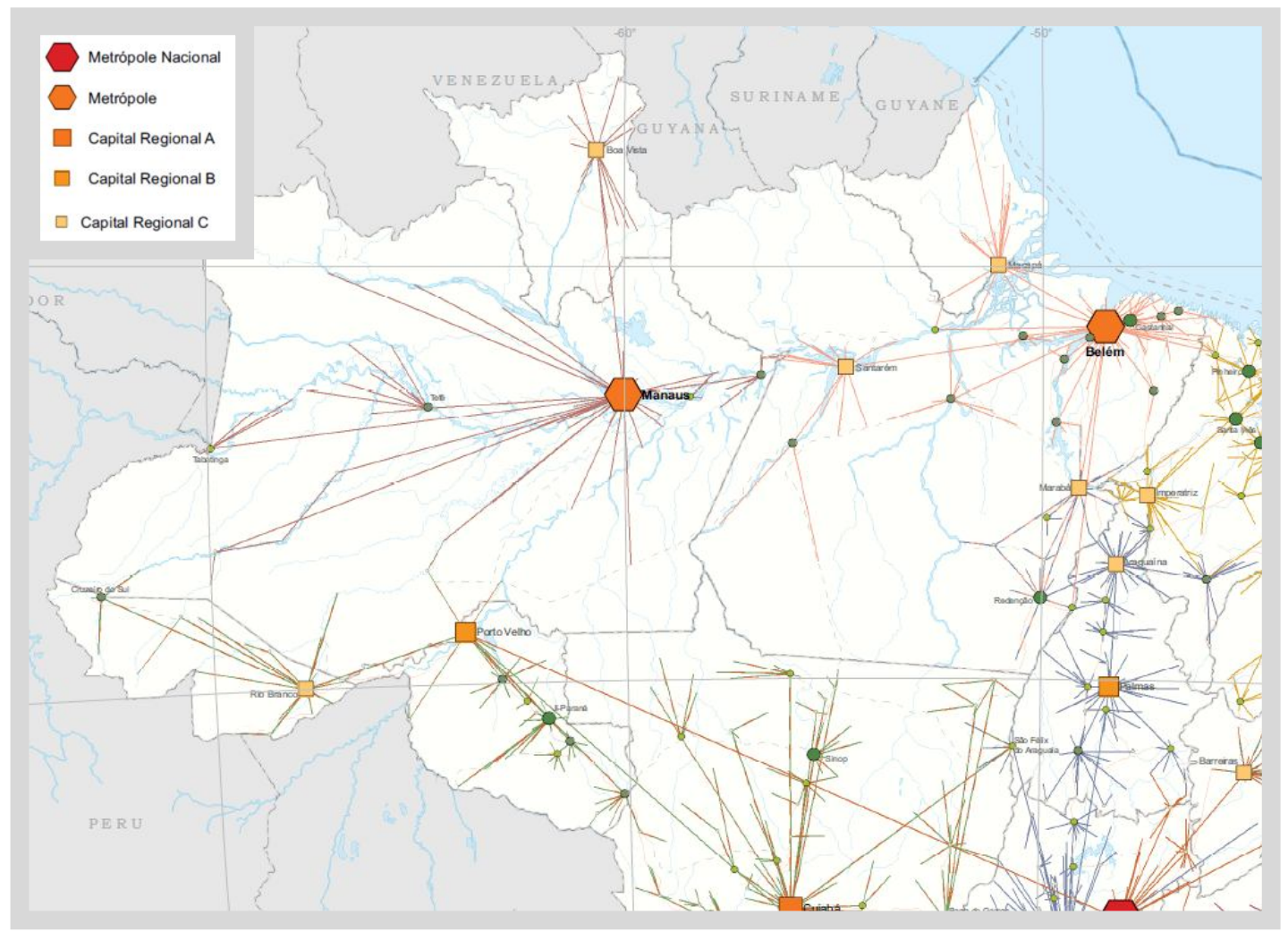

Fonte: IBGE (2008). 
A comparação entre os resultados do estudo do REGIC de 2007 (Figura 3) e as regiões metropolitanas instituídas na Região Norte (Figura 1), deixa evidente a situação desconforme das Regiões Metropolitanas de Central e do Sul de Roraima, ambas localizadas no estado de Roraima, com o estabelecido pelo Estatuto.

O Estatuto estipulou ainda, no Art. 5o, o conteúdo mínimo que devem ter as leis complementares estaduais que instituem regiões metropolitanas, que consiste: na relação dos municípios que integram a região; na explicitação das $\mathrm{FPICs}^{4}$ que a justificam; na definição da estrutura de governança interfederativa, incluindo a organização administrativa e o sistema integrado de alocação de recursos e de prestação de contas; e os meios de controle social da organização ${ }^{5}$. 0 Quadro 1 apresentado anteriormente, mostrou mesmo que de maneira sintética, que as leis que criaram as regiões metropolitanas da Amazônia se mostram inadequadas total ou parcialmente face aos requisitos estabelecidos pelo Estatuto.

Em dezembro de 2016 o M inistério das Cidades promoveu um seminário internacional, em Brasília, para discutir experiências de planejamento metropolitano. Das experiências brasileiras apresentadas, nenhuma cumpria todos os requisitos estabelecidos pelo Estatuto. Mesmo as Regiões Metropolitanas de Belo Horizonte e São Paulo, consideradas como as que mais avançaram na regulamentação, no planejamento e na gestão metropolitana no país não se acham totalmente adaptadas ao novo marco legal metropolitano nacional.

Diante deste quadro, quais os desafios que se colocam para as regiões metropolitanas da Amazônia visando à adaptação ao Estatuto da Metrópole e à retomada do tratamento da questão metropolitana?

\section{DESAFIOS PARA AS REGIÕES METROPOLITANAS AMAZÔNICAS}

As Regiões Metropolitanas instituídas na Amazônia terão que enfrentar inúmeros desafios para poderem alcançar o nível de gestão plena no âmbito metropolitano.

0 primeiro deles é o de adequação das leis de criação das regiões metropolitanas, até porque, embora o Estatuto da M etrópole reconheça as regiões criadas antes da sua aprovação, prevê que as que não atendam aos requisitos que institui não serão consideradas como de gestão plena para fins de apoio federal para ações de governança interfederativa de cunho metropolitano.

\footnotetext{
${ }^{4}$ As FPICs são definidas, pelo Estatuto das M etrópoles, no item II do Art. $2^{\circ}$ como "política pública ou ação nela inserida cuja realização por parte de um Município, isoladamente, seja inviável ou cause impacto em M unicípios limítrofes". (BRASIL, 2015)

${ }^{5}$ Como princípios para a governança metropolitana interfederativa, o Estatuto, em seu Art. 6으, estabelece: a prevalência do interesse comum sobre o local; o compartilhamento de responsabilidade para a promoção do desenvolvimento urbano integrado; a autonomia dos entes da Federação; a observância de peculiaridades regionais e locais; a gestão democrática da cidade; a efetividades no uso dos recursos públicos; e, a busca do desenvolvimento sustentável.
} 
Isso remete, inicialmente, para a necessidade urgente de desenvolvimento de estudos que identifiquem, realmente, onde há o fenômeno metropolitano e quais os municípios estão nele envolvidos no país, particularmente para a Amazônia onde as discrepâncias dos critérios adotados, como se observou, são imensas. Para isso, a definição de região metropolitana presente no Estatuto é insuficiente, pois está atrelada a uma visão de rede urbana de dimensão microrregional e não de escala metropolitana. É preciso estabelecer com mais clareza e objetividade os critérios para configuração das regiões metropolitanas e para inserção de municípios na mesma.

Entende-se que tais parâmetros deveriam ser unificados para todo o país, pois, só desta maneira, o governo federal poderia construir um sistema de informações metropolitanas consistente, que retratasse as regiões metropolitanas de todo o território nacional e que possibilitasse, inclusive via o estabelecimento de comparações, a construção de diagnósticos, a elaboração de políticas de âmbito nacional e a definição de estratégias e prioridades de atuação nas escalas nacionais e regionais. Isso não significa abandonar as peculiaridades regionais. Muito pelo contrário, representa considerá-las numa visão abrangente.

A partir destas definições cabe verificar até que ponto interessa manter, na Amazônia, regiões metropolitanas e/ ou municípios metropolitanos nas situações que não há o fenômeno metropolitano e/ ou que o município não está nele inserido.

Ao se analisar a história do planejamento e da gestão metropolitana no país verifica-se a importância que a alocação de recursos federais, mediante programas setoriais ou metropolitanos, têm para a implementação das FPICs, o que decorre em grande medida da ainda significativa centralização de recursos nas mãos da União. Deixar que os Estados e M unicípios definam sozinhos os critérios para a delimitação e institucionalização das regiões metropolitanas é uma estratégia que já se mostrou inadequada, pois resultou na criação de uma quantidade enorme de regiões e na necessidade de utilização de critérios paralelos, pela União, para a alocação dos recursos do Governo Federal em áreas metropolitanas. Reincidir neste equívoco resultará, em última instância, no enfraquecimento do próprio Estatuto, tornando-o mais uma Lei sem aplicabilidade.

O segundo grande desafio a enfrentar diz respeito ao financiamento das ações de caráter metropolitano. Considerando a limitada capacidade de inversão dos Estados e M unicípios da Amazônia, não se pode pensar em governança interfederativa sem a participação da União. Por outro lado, a tendência à redução das inversões públicas, dada a diminuição da capacidade de investimentos da União e de endividamento dos Estados, coloca a necessidade de pensar em mecanismos de indução de investimentos privados. Como consequência, ao lado da retomada da discussão da criação e constituição do Fundo M etropolitano, há que se enfrentar o debate de questões como às referentes à privatização, à formação de parcerias público-privada e à recuperação das mais valias urbanas. 
Como recuperar e integrar os investimentos setoriais de caráter metropolitano públicos (da União, Estado e Municípios) e privados e torná-los viáveis e sustentáveis do ponto de vista econômico, social e ambiental? Esta é uma questão que deverá entrar imediatamente na pauta dos debates regionais.

0 terceiro desafio de grande monta diz respeito à construção de mecanismos democráticos de governança interfederativa para o planejamento, a gestão e a execução das FPICs. É sabida a dificuldade de mobilizar atores urbanos de naturezas (pública e privada), poderes (econômico e político) e saberes desiguais. E mais ainda, de fazê-los pactuar manejando interesses muitas vezes contraditórios.

Como definir modelos de governança em situações em que o poder econômico e político são tão assimétricos? Como partilhar o poder entre estado e municípios? Como distribuir o poder decisório entre municípios quando a sede metropolitana é tão superior em termos econômicos, demográficos e técnicos aos demais municípios que integram a região metropolitana?

Acresce-se a isso, a inexistência, na região, de uma cultura metropolitana e a falta de sensibilidade política para os próprios ganhos de escala que os investimentos metropolitanos poderiam acarretar. Pensar instituições e instrumentos de planejamento e gestão metropolitanos que respeitem as especificidades locais e regionais, e que contribuam para a redução das desigualdades socioeconômicas e socioespaciais, poderia ser o ponto de partida e o caminho norteador do debate metropolitano na Amazônia.

Já no âmbito da nova estrutura de governança e com as fontes de recursos definidas, o desafio será integrar as agendas de planejamento territorial e setorial metropolitano com os planos diretores e setoriais de escala municipal. Para isso, necessário se faz definir, de modo mais preciso, e regulamentar os novos instrumentos para a gestão compartilhada: em especial o PDUI e os demais instrumentos previstos na Lei Federal no 13.089/2015. Isso não é tarefa fácil, pois depende, sobremaneira, de regulamentação em nível federal e da capacitação dos entes federativos da região para aplicá-los.

Por fim, vem o maior de todos os desafios, que é o de fazer isso tudo nos prazos estabelecidos pelo Estatuto. Para isso, o debate na Amazônia está muito atrasado.

\section{REFERÊNCIAS}

ALVES, Alaôr Caffé. Regiões metropolitanas, aglomerações urbanas e microrregiões: novas dimensões constitucionais da Organização do Estado Brasileiro. Revista da Procuradoria Geral do Estado de São Paulo, ed. especial, São Paulo, set. 1998. AM APÁ. Assembleia Legislativa. Lei Complementar no 21, 2003. AM AZONAS. Assembleia Legislativa. Lei Complementar no 52, 2007. BRASIL. Presidência da República. Lei Complementar no 14, 1973. . Presidência da República. Constituição Federal do Brasil, 1988. 
de Janeiro de 2015.

BRASIL. M inistério das Cidades. Regiões Metropolitanas: Reunião Técnica Regional Centro-Oeste e Norte. Brasília, 2015. Apresentação.

COUTINHO, Luiz Quental; PINTO, Luciano Alves; CRUZ, Jório. Sobre o Estatuto da Metrópole: apreciação e subsídios. Julho - 2009. Disponível em: বhttp://www.em plasa.sp.gov.br/fnem/Arquivos/Parecer\%20Recife.pdf>. Acesso em: 02 jan. 2015.

KAYSER, Bernard. A região como objeto de estudo da geografia. In: George, Pierre et al. A geografia ativa. São Paulo/ Rio de Janeiro: Difel, 1980.

LENCIONI, Sandra. Reconhecendo metrópoles. In. SILVA, C. A. et al (org). Metrópole: governo, sociedade e território. Rio de Janeiro: Ed. DP \& A, 2006.

LACERDA, Norma; ZANCHETI, Silvio M endes; DINIZ, Fernando. Planejamento Metropolitano: uma proposta de conservação urbana e territorial. EURE (Santiago), Santiago, v. 26, n. 79, dez. 2000.

OLIVEIRA, Janete M arília Gentil Coimbra de. Expansão Urbana e Periferização de Santarém-PA, Brasil: Questões para o planejamento Urbano. Diez años de câmbios em el M undo, em la Geografia y em las Ciencias Sociales, 1999-2008.Actas del X Coloquio Internacional de Geocrítica, Universidad de Barcelona, 26-30 may2008.

PARÁ. Assembleia Legislativa. Lei Complementar n 027, 1995.

. Assembleia Legislativa. Lei Complementar no 079, 2012.

PINHEIRO, Andrea de Cássia Lopes, et al. Desafios da Governança Metropolitana na Região Metropolitana de Belém: Alguns Apontamentos. In: COSTA, Marco Aurélio; MARGUTI, Bárbara Oliveira. 40 Anos de Regiões Metropolitanas no Brasil. Brasília: IPEA, 2014. p. 48 a 67.

RIBEIRO, Luiz Cesar de Queiroz; SANTOS JR, Orlando Alves dos; RODRIGUES, Juciano Martins. Estatuto da Metrópole: avanços, limites e desafios. Disponível em: বhttp://www.observatorio dasmetropoles.net/index.php?option=com_k2\&viem=item \&id $=1148 \% 3$ Aestatuto-da-metr\%C3\%pole-avan\%C3\%A7os-limites-edesafios\&itemid=180\&lang=pt >. Acesso em: 09 abr. 2015.

ROM ANELLI, Carla; ABIKO, Alex Kenya. Processo de Metropolização no Brasil. São Paulo: EPUSP, 2011. 34p. Disponível em «ttp://www.pcc.usp.br/files/text/publicati ons/TT_00028.pdf >. Acesso em: 26 mai. 2015.

RORAIM A. Assembleia Legislativa. Lei Complementar no130, 2007.

TOCANTINS. Assembleia Legislativa. Lei Complementar no 93, 2014.

Artigo recebido em 14 de julho de 2016.

Aprovado em 18 de julho de 2016. 